\title{
CENAS DO FILME “O JOGO DA IMITAÇÃO”: reflexões sobre a invisibilidade da dupla excepcionalidade no contexto social
}

Josilene Domingues Santos Pereira*

Rosemeire de Araújo Rangni**

\begin{abstract}
Resumo: O filme "O Jogo da Imitação" é baseado no livro "Alan Turing: the enigma” de Andrew Hodges. É uma cinebiografia do cientista, matemático e criptoanalista britânico, Alan Turing. O objetivo deste artigo é descrever cenas do filme que demonstram indicadores de uma condição reconhecida como dupla excepcionalidade pelos estudiosos da área de altas habilidades/superdotação. Adotou-se a análise fílmica como procedimento metodológico. Os resultados indicaram que essa condição foi imperceptível no meio social e escolar onde Alan Turing viveu. Além disso, percebe-se ainda que a invisibilidade dessa condição repercute no contexto social em críticas de cinema e em políticas educacionais brasileiras.
\end{abstract}

Palavras-chave: Altas Habilidades/Superdotação. Dupla excepcionalidade. Análise filmica.

\section{MOVIE SCENES FROM “THE IMITATION GAME”: reflections on the invisibility of double exceptionality in social contexts}

\begin{abstract}
The movie "The Imitation Game" is based on Andrew Hodges' book "Alan Turing: The Enigma", which is a biography of British scientist, mathematician and cryptanalyst Alan Turing. The purpose of this article is to describe scenes from the film that demonstrate indicators of a condition recognized as dual exceptionality by scholars in the area of high skills/giftedness. Movie analysis was adopted as methodological procedure. The results of the analysis indicated that this condition was imperceptible in the social and school environment where Alan Turing lived. In addition, it is verified realized that the invisibility of this condition can have repercussions on the social context in film critics and in Brazilian educational policies.
\end{abstract}

Keywords: Giftedness. Double exceptionality. Film analysis.

\footnotetext{
* Doutoranda em Educação Especial pela Universidade Federal de São Carlos - UFSCar. Docente do Instituto Federal de Educação, Ciência e Tecnologia da Bahia- campus Vitória da Conquista. E-mail: josilenesantos@ifba.edu.br e josidomingues.ifba@gmail.com

${ }^{* *}$ Doutora em Educação Especial pela Universidade Federal de São Carlos - UFSCar. Docente da Licenciatura e da PósGraduação em Educação Especial da Universidade Federal de São Carlos. E-mail: rose.rangni@uol.com.br
} 


\section{Considerações iniciais}

O filme O jogo da Imitação, em inglês, The Imitation Game, lançado em 2014, foi dirigido por Morten Tyldum e baseado no livro Alan Turing: the enigma de Andrew Hodges. Ele é uma cinebiografia do matemático, criptoanalista, lógico e cientista britânico Alan Turing.

Esse longa-metragem, com duração de 114 minutos, teve várias indicações ao Oscar, mas ganhou apenas na categoria de melhor roteiro adaptado. A trama retrata momentos (passado, presente e futuro) da vida de Alan Turing:

a) A adolescência, mostrada em flashbacks esporádicos ao longo da trama, passa-se no ano de 1928. O cenário desse periodo da narrativa é a escola Sherbourne, onde se constrói a relação de amizade com Christopher Morcom. Nesse momento, a peça fílmica mostra os constantes atos de violência sofridos por Alan Turing e praticados por seus colegas da escola. As cenas focalizam a convivência difícil e tumultuada que ele teve de enfrentar e os sofrimentos por que passou durante a adolescência.

b) O periodo da Segunda Guerra Mundial, em 1939/1940, quando ele se voluntariou para trabalhar no Government Code e CyperSchool em Bletchley Park com a função primordial de decifrar as mensagens codificadas e enviadas pela máquina alemã denominada Enigma.

c) O pós-guerra, em 1951, em Manchester (Inglaterra), quando Turing comeşa a ser investigado, porque alguém havia invadido a sua casa. No filme, o detetive encarregado quer estudar o caso, pois desconfia que "o arrogante professor universitário" é, na verdade, um espião soviético. É o período em que ocorre a sua condenação por prática homossexual que era, na época, considerada crime na Inglaterra. Ele foi condenado por indecência e teve de escolher entre um ano de castração hormonal ou dois anos na cadeia. Ele, então, opta pela castração, para poder continuar trabalhando em seus projetos.

A maior estrutura da narrativa do filme se concentra no periodo da segunda guerra, quando Alan Turing demonstra o seu alto potencial e criatividade ao projetar a construção de um equipamento, que decifrava, em tempo real, as mensagens transmitidas pelos alemães por meio de uma máquina automatizada de criptografia conhecida como Enigma. Estima-se que essa criação de Turing tenha diminuido em dois anos a duração da guerra e, além disso, tenha sido precursora do que se conhece atualmente como computador. Por isso, ele, na atualidade, também é conbecido como o pai da inteligência artificial e da ciência computacional.

O filme O Jogo da Imitação procura mostrá-lo como um matemático genial com dificuldades significativas de relacionamento e interação social. Desse modo, uma questão norteou este trabalho: Alan Turing era mesmo arrogante, problemático ou ele tinha algum déficit específico caracterizado por dificuldades de comunicação e interação social e que, normalmente, era mascarado por seu extraordinário talento na matemática?

Essa cinebiografia de Alan Turing, retratando algumas situações de sua vida, é a fonte de nossa análise neste artigo, cujo objetivo central é descrever cenas do filme que demonstram indicadores de uma condição reconhecida com dupla excepcionalidade pelos estudiosos da área de altas 
habilidades/superdotação. Para tanto, serão exploradas, nas cenas, as ações do protagonista, que interpreta Alan Turing e o contexto comunicativo na interação social entre Turing e os demais personagens do filme.

\section{Procedimentos metodológicos para a análise fílmica}

O processo de análise fílmica consiste em uma atividade que deve passar por uma desconstrução (descrição) de seus elementos constitutivos e reconstrução (interpretação) de suas partes constitutivas (VANOYE, 2008). No processo interpretativo, Flick (2009) recomenda a utilização de diferentes níveis de significado - as leituras realistas e subversivas-. Essas últimas dizem respeito às influências das ideias do analista, de sua leitura de mundo, ao passo que aquelas se referem à descrição detalhada do filme e que acaba revelando os conteúdos e os aspectos formais das imagens.

Com base nisso, foram adotados os seguintes procedimentos de análise (FLICK, 2009, p.224) conforme demonstra o quadro 1 :

Quadro 1: Etapas e procedimentos de análise

\begin{tabular}{|c|c|}
\hline Etapas & Procedimentos \\
\hline $\begin{array}{l}\text { Etapa 1: } \\
\text { Assistir e sentir o } \\
\quad \text { filme }\end{array}$ & $\begin{array}{l}\text { Nessa etapa, foram feitas várias visualizações e anotações de impressões do } \\
\text { filme. A intenção foi buscar padrões de significado visíveis e elaborar } \\
\text { hipóteses. }\end{array}$ \\
\hline $\begin{array}{c}\text { Etapa 2: } \\
\text { Focar na } \\
\text { elaboração da } \\
\text { questão de } \\
\text { pesquisa }\end{array}$ & $\begin{array}{l}\text { Formulam-se questões que devem ser buscadas no material e registram } \\
\text { anotações de cenas-chave: Por que, no filme, o protagonista que interpreta } \\
\text { Alan Turing apresenta dificuldades de interação social, de relacionamento? } \\
\text { Por que, um matemático genial, como Turing, é representado no filme com } \\
\text { dificuldades no que se refere à compreensão da linguagem figurada ou do } \\
\text { contexto comunicativo na interação social? Por que, no filme, várias cenas } \\
\text { apresentam essas dificuldades como características de um comportamento } \\
\text { excêntrico, pedante, problemático? }\end{array}$ \\
\hline $\begin{array}{l}\text { Etapa 3: Produzir } \\
\text { microanálises } \\
\text { estruturadas }\end{array}$ & $\begin{array}{l}\text { Foram realizadas microanálises estruturadas de cenas e de sequências } \\
\text { individuais. Para essas microanálises, foram recortadas cenas do filme e } \\
\text { analisadas com base no referencial teórico adotado. O objetivo dessa etapa } \\
\text { foi construir descrições e padrões detalhados na exposição de fragmentos. }\end{array}$ \\
\hline $\begin{array}{l}\text { Etapa } 4: \\
\text { Interpretar as } \\
\text { cenas }\end{array}$ & $\begin{array}{l}\text { A busca por padrões estendeu-se ao filme todo para responder às questões } \\
\text { de pesquisa. Leituras realistas e subversivas do filme foram contrastadas e } \\
\text { resultaram nas seguintes categorias: a) concepções sobre inteligência, altas } \\
\text { habilidades/superdotação e criatividade; b) o termo dupla excepcionalidade } \\
\text { em pesquisas sobre superdotação; c) dificuldades de interação comunicativa } \\
\text { no contexto social e d) fatores que contribuem para a invisibilidade da } \\
\text { dupla excepcionalidade. }\end{array}$ \\
\hline
\end{tabular}

Fonte: Elaborado pelas autoras. Adaptado de Denzin (2004 apud Flick, 2009). 


\section{Primeiro pano de fundo: concepções sobre inteligência, Altas Habilidades/ Superdotação $(\mathrm{AH} / \mathrm{SD})^{1}$ e criatividade}

Filósofos e pesquisadores propuseram várias concepções sobre a inteligência ao longo da história. Essas concepções impactaram também nos conceitos de altas habilidades/superdotação (AH/SD) e na relação estabelecida entre inteligência e criatividade (ALENCAR; FLEITH, 2001; GAMA, 2006).

Renzulli (1998) afirma que há muitos tipos de inteligência e, portanto, definições únicas não podem ser usadas para explicar a complexidade de aspectos que envolvem tal conceito. Esse fato fez com que alguns estudiosos como Sternberg propousesse a Teoria Triárquica da Inteligência Humana que consiste em considerar a associação da inteligência tanto ao mundo interno quanto externo do indivíduo, cuja experiência funciona como mediadora entre os dois mundos.

Importante destacar que vigora, na atualidade, uma visão multidimensional da inteligência, pois, de acordo com Sternberg (1999), já se acumulou um conjunto substancial de evidências que sugerem que a inteligência não é um construto unitário. Assim também se processa em relação ao conceito de AH/SD.

Renzulli (1998) assevera que o comportamento superdotado (termo utilizado pelo autor) deve ser considerado dentro do contexto de fatores culturais e situacionais e que não há uma maneira ideal de medir a inteligência e, por conta disso, deve-se evitar a prática comum de acreditar que se conhece a inteligência de uma pessoa com base no conhecimento que se tem de seu quociente de inteligência (QI). Com base nesses pressupostos, o autor propõe uma definição para comportamento superdotado que considera três conjuntos de traços inter-relacionados: habilidade geral acima da média, envolvimento com a tarefa e criatividade.

Esta última inclui fluência, flexibilidade, pensamento original, adaptação a novas experiências, curiosidade, assunção de riscos e sensibilidade estética. Assim, nessa perspectiva, a convergência entre inteligência, conhecimento, estilos de pensamento, personalidade, motivação e ambiente forma o comportamento superdotado criativo-produtivo (RENZULLI, 1998, 2014).

Ressalta-se que tem havido um interesse crescente por pesquisar a criatividade e a sua relação com a inteligência (ALENCAR, 2001; STERNBERG, 2017), mas ainda não há um “consenso acerca da extensão em que essa habilidade se diferencia da inteligência, ou, pelo contrário, constitui uma faceta da inteligência que não tem sido avaliada tradicionalmente pelos testes de inteligência" (ALENCAR; FLEITH, 2003, p. 13). No filme, foram observadas várias ações do protagonista que indicam a manifestação da criatividade, do envolvimento com a tarefa e da habilidade acima da média, os traços propostos por Renzulli (1998) em sua teoria sobre as AH/SD. Um desses exemplos pode ser identificado

\footnotetext{
${ }^{1}$ Neste trabalho, adota-se o termo altas habilidades/superdotação em consonância com a Política Nacional de Educação Especial na Perspectiva da Educação Inclusiva (2008). Serão mantidas, entretanto, as terminologias originais de autores e documentos.
} 
na cena 1 a seguir:

\section{Cena 1: Indicadores de criatividade}

Os membros da equipe se dedicam horas na decodificação dos códigos da máquina Enigma, mas Turing, diferentemente dos colegas, se dedica a construir outra máquina, cuja função seria decifrar em tempo real as mensagens enviadas pela Enigma aos submarinos alemães.

Nota-se que, na análise dessa cena, Alan Turing, demonstra além de um pensamento divergente, uma acentuada dedicação e envolvimento com a tarefa. A ideia de projetar um aparelho que pudesse decifrar em tempo real as mensagens enviadas aos submarinos alemães é inovadora e criativa, já que sua máquina deveria ser capaz de testar combinações rapidamente e obter a chave de decifração das mensagens geradas pelo dispositivo alemão.

Essa criação de Alan Turing constitui-se, pois, em um produto criativo, considerando a definição proposta por Amabille (1983, p. 360), segundo a qual “um produto ou resposta será julgado como criativo se (a) for ao mesmo tempo uma novidade e uma resposta apropriada, útil, correta ou válida para uma tarefa específica, e (b) a tarefa é heurística mais do que algorítmica".

Além de uma novidade, essa criação de Turing causou uma mudança irreversível no meio social não só pela validade útil da máquina, que diminuiu em dois anos a Segunda Guerra Mundial, mas também pelo fato de esse produto criativo ser o precursor do que hoje se conhece como computador. A engenhosidade de Turing mudou o contexto da época e ainda construiu as bases para uma transformação sociocultural nas gerações posteriores.

\section{Segundo pano de fundo: o termo dupla excepcionalidade em pesquisas sobre superdotação}

A dupla excepcionalidade tem sido definida como a presença concomitante de alta capacidade, habilidade, potencial em uma área ou mais e de alguma desordem física, sensorial, psiquiátrica (ALVES; NAKANO, 2015; PFEIFER, 2015).

De acordo com Coleman, Harradine e King (2005), foi Gallanger quem usou o termo pela primeira vez para designar alunos que apresentavam a coexistência de alto potencial e alguma deficiência ${ }^{2}$. Tal afirmação é corroborada por Prior (2013), ao defender que, apesar de haver referências, na literatura científica, aos estudantes identificados com talentos especiais e déficits desde 1923, foi realmente Gallanger quem cunhou o termo, em 1975, pela primeira vez.

Reis, Baum e Burke (2014) enfatizam que o termo dupla excepcionalidade ainda resulta em

\footnotetext{
${ }^{2}$ Nos Estados Unidos, devido à promulgação da legislação da educação especial em 1975, conhecida como Lei de Educação para os Indivíduos com Deficiências (IDEA), o termo deficiência refere-se à presença de deficiências (física, visual, auditiva, múltipla, intelectual), transtornos e, inclusive, distúrbios emocionais. O público-alvo da Educação Especial é mais amplo do que no Brasil. Neste trabalho, o uso do termo deficiências refere-se à presença de deficiência, transtornos e síndrome ou distúrbio.
} 
confusão e crítica especialmente fora da área da educação de estudantes com AH/SD, tendo em vista que ainda há profissionais que consideram os termos déficit e dotação incompatíveis, sendo assim, as mencionadas autoras propõem uma conceituação que tem como objetivo central fornecer claramente um retrato de traços e necessidades desses estudantes.

Para elas, estudantes com dupla excepcionalidade são aqueles que demonstram alto potencial de realização ou ainda produto criativo em um ou mais áreas, tais como matemática, artes, ciências e outros e que, ao mesmo tempo, apresentam uma ou mais deficiências (sejam sensoriais, sejam físicas), problemas emocionais ou transtornos (de aprendizagem, do espectro autista, de déficit de atenção ou hiperatividade) (REIS; BAUM; BURKE, 2014). No filme em tela, observam-se cenas que denotam indicadores de déficits acentuados na interpretação do contexto comunicativo e social.

\section{Cena 2: Indicadores de déficits na interpretação do contexto comunicativo e situacional}

Alan Turing chega a Bletchey Park para preencher uma vaga e trabalhar no Programa de Decifração da máquina alemã Enigma. Ele aguarda ser entrevistado pelo comandante da marinha real na própria sala do comandante. Notam-se problemas na construção dos sentidos por Turing, seja da linguagem verbal seja do próprio contexto situacional, pois, mesmo desejando trabalhar no projeto desenvolvido em Bletchey, as respostas dele ao comandante são interpretadas pelo chefe da marinha real como contrárias à sua intenção.

$\mathrm{Na}$ cena em análise, além de respostas inapropriadas ao contexto social e comunicativo, a ponto de o entrevistador pensar que o matemático estivesse ironizando a situação quando pergunta: "Isso é uma piada, senhor Turing?”, notaram-se ainda as dificuldades de interação social recíproca pelos indícios verbais e não verbais usados por Turing no diálogo. Ao término, quando o comandante sinaliza o encerramento da entrevista, indicando que não iria contratá-lo para o serviço, ele argumenta dizendo: “É minha mãe sempre diz que sou desagradável às vezes, apesar de ser um dos melhores matemáticos do mundo".

Com base nisso, deve-se questionar: Alan Turing, com seu potencial superior na matemática e seu excepcional desempenho criativo, demonstrando um talento extraordinário, também apresentava déficits a ponto de se confirmar um quadro de transtorno invasivo do desenvolvimento como o transtorno do espectro autista, indicando uma condição denominada dupla excepcionalidade? 
Terceiro pano de fundo: o que poderiam indicar essas dificuldades de interação comunicativa no contexto social?

A produção cinematográfica em análise foi baseada em uma biografia de Alan Turing. Pode-se, então, sugerir que as dificuldades de relacionamento, de interação social e comunicação, representadas pelo personagem central, refletem a personalidade real do extraordinário matemático britânico? O’Connell e Fitzgerald (2003) buscaram informações detalhadas na biografia de Turing e analisaram algumas histórias e fatos da vida do cientista que corroborariam um quadro de Síndrome de Asperger ${ }^{3}$ (SA).

De acordo com esses autores, há uma ampla evidência, ao longo da vida de Turing, que confirmariam uma indicação de Síndrome de Asperger. O`Connel e Fitzgerald (2003) elaboraram uma descrição de comportamentos desse extraordinário matemático:

a) Imposição de rotina a si mesmo e aos outros: Alan sempre comia uma maçã antes de deitar à noite; $\mathrm{O}$ espaço doméstico refletia seus interesses habituais (quando se interessava por Biologia, a casa ficava repleta de potes e panelas contendo ervas daninhas; quando trabalhava na máquina de calcular, o piso do quarto era completamente preenchido com engrenagens). No filme, percebeu-se essa imposição de rotina a si mesmo e aos outros quando se observou o ambiente doméstico do cientista:

\section{Cena 3: Indicativos de imposição de rotina a si mesmo e aos outros}

Nas cenas que apresentam o espaço físico da residência de Alan, pode-se ver a casa, em vários cômodos, repleta de materiais de pesquisa, esboços, desenhos e esquemas pendurados nas paredes.

b) Problemas de comunicação não verbal: Turing demonstrava uso limitado de gestos, linguagem corporal desajeitada, expressão facial limitada, olhar fixo peculiar e expressões inapropriadas à situação social e comunicativa.

c) Problemas na fala e uso da linguagem: linguagem expressiva excessivamente formal pedante, prejuízos na compreensão, incluindo interpretações erradas de significados implícitos. Em relação a este último, por exemplo, no filme, vemos esse problema quando os colegas da equipe avisaram que iriam almoçar:

\footnotetext{
${ }^{3} \mathrm{Na}$ atual publicação do DSM-V da Associação Americana de Psiquiatria (2014), "indivíduos com um diagnóstico do DSM-IV bem estabelecido de transtorno autista, Síndrome de Asperger ou transtorno global do desenvolvimento sem outra especificação devem receber o diagnóstico de transtorno do espectro autista" (APA, 2014, p. 51). A atual classificação da Associação Americana de Psiquiatria inclui a Síndrome de Asperger dentro do espectro do transtorno do autismo. Optamos por utilizar o termo Síndrome de Asperger em concordância com os autores que fizeram pesquisas sobre a biografia de Alan Turing.
} 


\section{Cena 4: Problemas na interpretação de significados implícitos}

Os membros da equipe expõem que estão com fome. Um deles se dirige a Alan Turing e diz que estão saindo para almoçar. Era um convite para que Alan fosse junto com eles, mas ele permanece envolvido com a tarefa que estava fazendo. Repete-se novamente a fala e o colega questiona a Alan se ele estava ouvindo. Ele responde que estava, mas o seu colega não entende o porquê daquela atitude. Quando o colega "traduz" o que havia dito, Turing então diz ao colega que ele não o havia convidado para o almoço.

d) Prejuízos na interação social recíproca: inabilidade e falta de desejo de interagir com os pares, dificuldaddes de apreciação de pistas sociais e comportamento social e emocional inapropriados. Várias cenas do filme indicam que Alan Turing tinha dificuldades no que diz respeito à interação social, à reciprocidade social e emocional, ao trabalho em equipe, à empatia.

É válido ressaltar que o comportamento excêntrico, as dificuldades de relacionamento, de interação e de compreensão de pistas sociais, o isolamento, eram atribuídos ao talento extraordinário ou ainda a um comportamento esnobe, pedante. No filme, exceto Joan Clarke e o amigo Christopher Morcom, todos os demais encontraram dificuldades para interagir e se relacionar com Alan.

A partir dessa análise, é necessário considerar os motivos pelos quais esses déficits de Alan Turing não eram percebidos como sinais de um transtorno concomitante ao seu talento notável. De acordo com Neihart (2000, p. 223), há várias semelhanças entre crianças com AH/SD e crianças com Síndrome de Asperger:

a) Fluência verbal e precocidade, além de excelente memória;

b) Interesse acentuado por letras, números e prazer em memorizar fatos em idade precoce;

c) Demonstram interesse por um tema específico e adquirem um vasto repertório de informações sobre o tópico que os fascina;

d) Hipersensibilidade a estímulos sensoriais, como texturas, ruídos, toques e sabor de alimentos;

e) Discrepância entre distintos aspectos do desenvolvimento como, por exemplo, o cognitivo e o social e o afetivo;

f) Apresentam grande variedade de habilidades, com excelente desempenho em áreas de interesse especial, paralelamente a um desempenho mediano em outras áreas.

Neihart (2000), no entanto, ressalta que existem diferenças entre crianças com SA e crianças com AH/SD e SA. Para tanto, deve-se considerar a história do desenvolvimento da criança e a observação dos motivos que estão por trás de determinados comportamentos. A autora propõe ainda nove aspectos diferenciais que devem ser levados em conta para distinguir a criança com AH/SD apenas da criança com AH/SD e Síndrome de Asperger, tais como: o padrão de fala, autoconsciência das diferenças, humor, dificuldades atencionais, respostas à rotina, a afetividade, as estereotipias e a percepção das pistas 
interacionais e contextuais e coordenação motora.

\section{Quarto pano de fundo: alguns fatores que produzem a invisibilidade da dupla excepcionalidade no contexto social}

A linguagem fílmica, além de nos auxiliar a analisar a vida social sob outros olhares também nos ajuda a interpretá-la, por meio da transposição da narrativa para a nossa realidade sociocultural. Em razão disso, observamos, na produção cinematográfica analisada, a repercussão da invisibilidade da condição da dupla excepcionalidade tanto por parte daqueles que conviveram com Alan Turing quanto por aqueles que fizeram críticas ao filme na internet.

Algumas críticas de cinema (BORGO, 2014; VILLAÇA, 2015), por exemplo, retrataram Alan Turing como um homem arrogante, pedante, problemático, um completo antissocial, socialmente deficiente, desajustado, gênio excêntrico e estranho. Dessa maneira, no contexto social, às dificuldades de interação social de Turing foram atribuídos, de modo injustificável, juízos de valor que, no imaginário social, passam a construir representações identitárias pejorativas do brilhante cientista britânico. Dessa constatação, algumas questões precisam ser problematizadas: por que é tão difícil identificar a condição de dupla excepcionalidade?

Esse quadro, formado pela junção de AH/SD e alguma deficiência e/ou transtorno, revela uma população única na área de $\mathrm{AH} / \mathrm{SD}$, pois os estudantes tendem a falhar em demonstrar alto desempenho acadêmico ou ainda em revelar alguma deficiência e/ou transtorno específico, já que suas potencialidades podem ser mascaradas por alguma deficiência e/ou transtorno ou, então, o contrário, a deficiência e/ou transtorno pode mascarar as AH/SD (REIS; BAUM; BURKE, 2014).

Vilarinho-Rezende, Fleith e Alencar (2016) afirmam também que realizar a distinção entre o quadro de superdotação e o de dupla excepcionalidade, além de um desafio para os profissionais que atuam na área da Educação Especial, é uma tarefa difícil, devido às características semelhantes entre a AH/SD e a SA (ALENCAR; GUIMARÃES, 2012) e isso, de fato, promove dificuldades no processo de avaliação das duas especificidades.

Para Alves e Nakano (2015), há outros fatores também que dificultam uma avaliação para a identificação da dupla excepcionalidade:

a) Escassez de estudos sobre a dupla excepcionalidade no contexto brasileiro;

b) Perpetuação do mito segundo o qual pessoas com AH/SD não apresentam dificuldades emocionais, comportamentais, educativas;

c) Ausência de preparação nos profissionais das diversas áreas da saúde e da educação para reconhecer que pessoas com algum tipo de deficiência e/ou comprometimentos funcionais possam ter talentos, habilidades especiais;

d) História recente da descoberta da condição da dupla excepcionalidade, datada em 1975, a partir dos trabalhos de Gallanger; 
e) Inexistência de uma teoria que explique a condição da dupla excepcionalidade.

Esses fatores, de certo modo, dificultam a identificação da dupla excepcionalidade e repercutem no meio social, promovendo a invisibilidade dessa condição. Uma consequência disso, no contexto social, é a criação e reprodução de imagens identitárias com valoração negativa, conforme se observou nos meios midiáticos pelas críticas de cinema.

Além disso, no filme, as cenas que retratam o período da adolescência demonstram várias situações de violência (bullying) sofridas por Alan Turing na escola Sherbourne. Na cena do refeitório na escola, a fala de Turing revela que as práticas de violência contra ele começaram devido à rotina fixa de comportamento, baseada no padrão repetitivo de separar as cenouras das ervilhas em função das cores.

\section{Post Scriptum: repercussões da invisibilidade da dupla excepcionalidade no contexto educacional}

O filme O Jogo da Imitação, apesar de ser uma produção cinematográfica e uma adaptação da obra Alan Turing: the enigma de Andrew Hodges, retrata fatos da vida do talentoso cientista britânico que merecem significativas reflexões, principalmente por mostrar os enfrentamentos, os problemas, os conflitos, as dificuldades sociais e emocionais a que estão submetidas pessoas com dupla excepcionalidade.

Dessa maneira, considerando a análise fílmica realizada, pode-se ainda realizar uma transposição dessa obra cinematográfica para o meio social brasileiro, mais especificamente para contexto educacional. A invisibilidade da dupla excepcionalidade repercute também nas políticas públicas que legislam sobre a Educação no país.

A área das Altas habilidades/Superdotação (AH/SD) passa a ser legalmente referenciada na educação brasileira em 1971 na Lei 5692/71 (BRASIL, 1971), que regulamenta a obrigatoriedade de atendimento a esse grupo de estudantes.

Os direitos dos estudantes com AH/SD ainda foram assegurados em outros documentos oficiais que os especificam dentro do público-alvo da Educação Especial (BRASIL, 1996). Na Política Nacional de Educação Especial na Perspectiva da Educação Inclusiva (BRASIL, 2008) ${ }^{4}$, os estudantes com AH/SD são compreendidos como aqueles que apresentam potencial elevado, isolado ou combinado, nas áreas: intelectual, psicomotricidade, acadêmica, liderança e artes. Além disso, também apresentam as seguintes características: criatividade, intenso envolvimento na aprendizagem e na realização de atividades em áreas de seu interesse (BRASIL, 2008).

Massuda e Rangni (2017, p. 92), tomando como base a definição dos vocábulos excepcionalidade

\footnotetext{
${ }^{4}$ A Política Nacional de Educação Especial (BRASIL, 1994) fez menção às Altas habilidades associada à condição de deficiência ou transtorno em seus objetivos específicos.
} 
e excepcional, explicam que, no contexto brasileiro, convive-se com a ambiguidade do termo excepcionalidade, uma vez que este significa qualidade de excepcional. Tal vocábulo pode indicar tanto exceção, excêntrico, incomum, quanto excelente, extraordinário, privilegiado e é utilizado para designar alguém que esteja acima da média comum quanto àqueles indivíduos abaixo da média, podendo ainda se referir a pessoas com algum tipo de deficiência.

No âmbito da legislação brasileira, sabe-se que a palavra excepcional foi utilizada até o início da década de $1970^{5}$ e era usada tanto para indicar os educandos com AH/SD quanto aqueles com deficiência. A partir de 1986, a expressão aluno excepcional é substituída definitivamente e adotada a expressão educando com necessidades especiais ${ }^{6}$. Tornou-se frequente, entretanto, atualmente, o uso do termo público-alvo da Educação Especial (PAEE) após a publicação da Política Nacional da Educação Especial, que passou a substituir os dois termos anteriores (MASSUDA; RANGNI, 2017).

As mencionadas autoras ainda assinalam que, por conta da adoção das nomenclaturas que substituíram a palavra excepcional dos documentos oficiais, não é comum o uso da expressão aluno excepcional entre os educadores brasileiros e que isso produz significativos obstáculos quer na identificação quer no atendimento aos alunos que comportam concomitantemente as AH/SD e alguma deficiência (física, sensorial, auditiva, visual), algum transtorno funcional ou transtorno global do desenvolvimento.

Nota-se que o termo PAEE, conforme salientam Massuda e Rangni (2017), não contempla esse grupo de educandos e isso claramente compromete a identificação e, por conseguinte, o atendimento aos estudantes com dupla excepcionalidade. Nesse sentido, pode-se claramente verificar que a legislação atual brasileira sequer cogita esse público, corroborando mais ainda para a reprodução social da invisibilidade dessa condição.

Esse dado nos permite repensar a respeito da invisibilidade da dupla excepcionalidade no contexto educativo. Quantos "Alans Turing” reais estão sendo ignorados em nossas escolas? Será que Turing teria passado por tantas situações de bullying na escola se a condição da dupla excepcionalidade não fosse invisível aos olhos de professores, diretores e psicólogos escolares? Sem identificar e sem sequer cogitar a realidade dessa condição, como vimos nos documentos que legislam sobre a Educação Especial no país, como atender alunos com dupla excepcionalidade em suas necessidades educacionais?

A análise desse filme, desse modo, demonstra que o tema precisa ser estudado, principalmente em se tratando da escassa produção de conhecimento sobre a condição da dupla excepcionalidade no Brasil. Dessa forma, sugere-se que futuros estudos na área das AH/SD explorem essa temática no âmbito da Educação Especial.

\footnotetext{
${ }^{5}$ Na Lei de Diretrizes e Bases da Educação (LDB) de 1971, a palavra excepcional já não é mais utilizada para indicar as pessoas que deviam ser atendidas pela Educação Especial.

${ }^{6}$ Portaria do CENESP/MEC, nº 69 , de 28 de agosto de 1986.
} 


\section{Referências}

ALENCAR, E. M. L. S.; GUIMARÃES, T. M. Dupla excepcionalidade, Superdotação e Transtorno de Asperger: contribuições teóricas. Revista Amazônica. v. 10, n. 3, Jul-Dez 2012, p. 95-108. Disponível em: https://dialnet.unirioja.es/servlet/articulo?codigo=4047470. Acesso em: 05 de maio 2018.

ALENCAR, E.S. Criatividade e Educação de Superdotados. Petrópolis, RJ: Vozes, 2001, 229 p.

ALENCAR, E.M. L. S.; FLEITH, D. S. Superdotados: determinantes, educação e ajustamento. 2.ed. São Paulo: EPU, 2001, 190p.

Criatividade: múltiplas perspectivas. 3.ed. Brasília: Editora Universidade de Brasília, 2003, 220

p.

AMABILE, T. M. The social psychology of creativity: a Componential Conceptualization. Journal of Personality and Social Psychology, v. 45, n. 2, p. 357-376, 1983. Disponível em: https://www.researchgate.net/publication/232529263 The Social Psychology of Creativity A Com ponential Conceptualization. Acesso em: 31 de maio de 2018.

ALVES, R. J. R.; NAKANO, T. C. A dupla-excepcionalidade: relações entre altas habilidades/superdotação com a síndrome de Asperger, transtorno de déficit de atenção e hiperatividade e transtornos de aprendizagem. Revista da Associação Brasileira de Psicopedagogia., São Paulo, v. 32, n. 99, p. 346-360, 2015.

Disponível em: <http://pepsic.bvsalud.org/scielo.php?script=sci_arttext\&pid=S010384862015000300008\&lng=pt\&nrm=iso >. Acesso em: 26 de maio 2018.

AMERICAN PSYCHIATRIC ASSOCIATION (APA). Diagnostic and Statistical Manual of Mental Disorders. 4. ed. text revision (DSM-IV-TR). Washington (DC): American Psychiatric Association, 2000, p. 69-84.

AMERICAN PSYCHIATRIC ASSOCIATION (APA). Manual Diagnóstico e Estatístico de Transtornos Mentais, DSM-V. Tradução de Maria Inês Corrêa Nascimento et al. 5.ed. Porto Alegre: Artmed, 2014, p. 50-59.

BORGO, E. O Jogo da Imitação. 2014. Disponível em: https://omelete.com.br/filmes/criticas/o-jogo-da-imitacao. Acesso em: 06 de maio 2018.

BRASIL. Lei no 5.692/71, de 11 de agosto de 1971. Fixa as Diretrizes e Bases para o Ensino de $\mathbf{1}^{\mathbf{o}}$ e $2^{\mathbf{o}}$ Graus e dá outras Providências. Brasília: MEC, 1971. Disponível em: http://www.camara.gov.br/sileg/integras/136683.pdf>. Acesso em: 05 de maio 2018.

BRASIL. Política Nacional de Educação Especial. Ministério da Educação e do Desporto. Secretaria de Educação Especial. Educação Especial. Um direito Assegurado, Livro 1, 1994. 66p.

BRASIL. Política nacional de Educação Especial na Perspectiva da Educação Inclusiva. Brasília. MEC/SEESP, $2008 . \quad$ Disponível em:

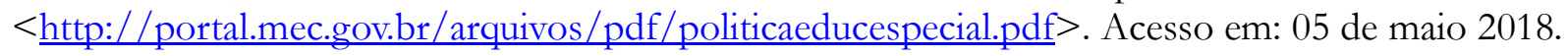

. Portaria no 69, de 28 de agosto de 1986. Regulamenta a Portaria Interministerial no 186, de março de 1977. Expede Normas para a Fixação de Critérios Reguladores da Prestação de Apoio Técnico e/ou Financeiro à Educação Especial nos Sistemas de Ensino Público e Particular. Brasília: MEC, 1986. 
COLEMAN, M. R.; HARRADINE, C.; KING, E. W. Meeting the needs of students Who are twice exceptional. Teaching Exceptional Children, v. 38, n. 1, 2005. Disponível em: http://goo.gl/0OTmLv. Acesso em: 25 de abril de 2018.

FLICK, U. Introdução à Pesquisa Qualitativa. Tradução Joice Elias Costa. 3.ed. Porto Alegre: Artmed, 2009.

GAMA, M. C. S. S. Educação de Superdotados: teoria e prática. São Paulo: EPU, 2006, 175p.

MASSUDA, M. B.; RANGNI, R. A. Altas habilidades ou superdotação e dupla excepcionalidade: definições e reflexões. In: RANGNI, R. A.; MASSUDA, M. B.; COSTA, M. P. R. (orgs.). Altas Habilidades/Superdotação: temas para pesquisa e discussão. São Carlos: EdUFSCar, 2017, p. 89-125.

NEIHART, M. Gifted children with Asperger's Syndrome. Gifted Child Quarterly, v. 44, 2000, p. 222-230. Disponível em: http://journals.sagepub.com.ez31.periodicos.capes.gov.br/doi/pdf/10.1177/001698620004400403 . Acesso em: 05 de abril de 2018.

O JOGO DA IMITAÇÃO. [Filme-Vídeo]. Produção de Teddy Schwarzman e Graham Moore. Direção de MortenTyldum. EUA, Grã-Betanha e Irlanda do Norte: 2014. (114 min.).

O’ CONNEL, H.; FITZGERALD, M. Did Alan Turing have Asperger's Syndrome? Irish Journal of Psychological Medicine, v. 20, n. 1, p. 28-31, mar. 2003. Disponível em: https://www.researchgate.net/publication/240630019. Acesso em: 05 de abril de 2018.

PFEIFFER, S. I. Gifted students with a coexisting disability: the twice exceptional. Estudos de Psicologia (Campinas), v. 32, n. 4, p. 717-727, Dec. 2015.

Disponível em: <http://www.scielo.br/scielo.php?script=sci_arttext\&pid=S0103166X2015000400717\&lng $=$ en\&nrm=iso $>$. Acesso em: 29 de abril de 2018. http://dx.doi.org/10.1590/0103-166X2015000400015.

PRIOR, S. Transition and students with twice excepcionality. Australian Journal of Special Education, v. 37, n. $1, \quad$ p. $19-27, \quad 2013 . \quad$ Disponível em: <HTTP:// epubs.scu.edu.au/CGI/viewcontent.cgi?article=1131\&context=c-cyp_pubs $>$. Acesso em: 17 de abril de 2018.

REIS, S. M.; BAUM, S. M.; BURKE, E. An Operational Definition of Twice- Exceptional Learners: Implications and Applications. Gifted Child Quarterly, v. 58, n. 3, 2014, p. 217-230. Disponível em: http://journals.sagepub.com.ez31.periodicos.capes.gov.br/doi/pdf/10.1177/0016986214534976.

Acesso em: 15 de abril de 2018.

RENZULLI, J. S. Three-Ring Conception of Giftedness. In: BAUM, S. M.; REIS, S. M.; MAXFIELD, L. R. (orgs.) Nurturing the gifts and talents of primary grade students. Mansfield Center, CT: Creative Learning Press, 1998. Disponível em: < https://www.researchgate.net/publication/237668711 The Three-Ring Conception of Giftedness A Developmental Model For Promoting Creative Productivity. Acesso em: 26 de abril de 2018.

RENZULLI, J. Modelo de enriquecimento para toda a escola: um plano abrangente para o desenvolvimento de talentos e superdotação. Revista Educação Especial, Santa Maria, p. 539-562, nov. 2014. Disponível em: < https://periodicos.ufsm.br/educacaoespecial/article/view/14676>. Acesso em: 02 de setembro de 2018. doi:http://dx.doi.org/10.5902/1984686X14676.

STERNBERG, R. J. The theory of successful intelligence. Review of General Psychology, v. 3, n. 4, 1999, p. 
292-316. Disponível em: http://psycnet-apa-org.ez31.periodicos.capes.gov.br/fulltext/1999-01689003.pdf. Acesso em: 15 de abril de 2018.

VANOYE, F.; GOLIOT-LÉTÉ, A. Ensaio sobre a Análise Fílmica. Trad. de Marina Appenzeller. 5. ed. Campinas: Papyrus, 2008.

VILARINHO-REZENDE, D.; SOUZA FLEITH, D.; ALENCAR, E. M. L.S. Desafios no diagnóstico de dupla excepcionalidade: um estudo de caso. Revista de Psicología, Lima , v. 34, n. 1, p. 61-84, 2016 - Disponível em: $\quad<$ http://www.scielo.org.pe/scielo.php?script=sci_arttext\&pid=S025492472016000100004\&lng $=$ es\&nrm $=$ iso $>$.

Acesso em: 05 de maio de 2018. http://dx.doi.org/10.18800/psico.201601.003.

VILLAÇA, P. O Jogo da Imitação. 2015. Disponível em: http://cinemaemcena.cartacapital.com.br/Critica/Filme/2641/o-jogo-da-imitacao.

Acesso em: 07 de maio de 2018. 